\title{
Assessment of the types of catheter infectivity caused by Candida species and their biofilm formation. First study in an intensive care unit in Algeria
}

\author{
This article was published in the following Dove Press journal: \\ International Journal of General Medicine \\ 8 January 2013 \\ Number of times this article has been viewed
}

\author{
Sidi Mohammed Lahbib \\ Seddikil \\ Zahia Boucherit-Otmani' \\ Kebir Boucherit ${ }^{\prime}$ \\ Souad Badsi-Amir ${ }^{2}$ \\ Mourad Taleb ${ }^{3}$ \\ Dennis Kunkel ${ }^{4}$ \\ 'Laboratory: Antifungal Antibiotic, \\ Physico-Chemical Synthesis and \\ Biological Activity, University of \\ Tlemcen, Algeria; ${ }^{2}$ Department of \\ Anesthesiology, ${ }^{3}$ Department of \\ Epidemiology, University Hospital of \\ Sidi Bel Abbes, Algeria; ${ }^{4}$ Dennis Kunkel \\ Microscopy Inc, Kailua, HI, USA
}

Correspondence: Sidi Mohammed Lahbib Seddiki

Laboratoire Antibiotique Antifongique, University of Tlemcen, BP I I 9, Imama 13000 - Tlemcen and the University

Center of Naama 45000 - Naama, Algeria

$\mathrm{Tel}+213662699682$

Fax +21349797640

Email sdadek@hotmail.com

\begin{abstract}
Nosocomial candidiasis remains a potential risk in intensive care units (ICUs), wherein Candida albicans is most responsible for its occurrence. Equally, non-C. albicans species, especially $C$. glabrata, are also involved. These infections are frequently associated with biofilms that contaminate medical devices, such as catheters. These biofilms constitute a significant clinical problem, and cause therapeutic failures, because they can escape the immune response and considerably decrease sensitivity to antifungal therapy. The diagnosis of catheter-related candidiasis is difficult; however, the differentiation between an infection of the catheter (or other medical implant) and a simple contamination is essential to start an antifungal treatment. Among the methods used for this type of study is the Brun-Buisson method, but this method only examines the infectivity of catheters caused by bacteria. For this reason, we wanted to adapt this method to the yeast cells of Candida spp. To assess the various types of infectivity of catheters (contamination, colonization, or infection) and their corresponding rates, as well as the responsible yeast species, we conducted our study, between February 2011 and January 2012, in the ICU at the University Hospital Center of Sidi Bel Abbes, Algeria; during this study, we took photographic images of the tongue of one patient and of that patient's implanted orobronchial catheter. In addition, catheters contaminated by C. albicans biofilms were observed by scanning electron microscopy.
\end{abstract}

Keywords: ICU, contamination, colonization, infection

\section{Introduction}

Nosocomial invasive candidiasis is a major problem, associated with significant mortality, ${ }^{1,2}$ that affects $15 \%$ of nosocomial infections in patients hospitalized in intensive care units (ICUs). ${ }^{3}$ Clinical signs of such infections appear late, rendering them difficult to diagnose. ${ }^{3,4}$ Many yeasts are opportunistic pathogens, ${ }^{5}$ and Candida albicans is the most common of these to colonize, but non-albicans species of Candida are increasingly involved in infection, ${ }^{6-8}$ in particular, C. glabrata, an emerging species associated with high mortality. ${ }^{9}$ Compared with $C$. albicans fungemia, the impact of C. glabrata fungemia on patients in the ICU is not well known. ${ }^{10}$

Candidemia is frequently associated with the colonization of medical devices, such as catheters. ${ }^{11}$ In addition, a factor that is generally predisposing to invasive candidiasis in the ICU is the alteration of skin and mucus barriers caused by the use of medical devices (catheters, probes, intubation, etc). ${ }^{12}$ Further, the resistance of Candida spp. to antifungal agents increases with the formation of biofilms into medical implants. ${ }^{13-15}$ 
Indeed, Candida colonization appears to be a prerequisite for Candida infection; ${ }^{16}$ therefore, it is important to distinguish between simple contamination, colonization, and infection of catheters, ${ }^{6,17}$ because this differentiation remains crucial in initiating treatment. ${ }^{18} \mathrm{~A}$ threshold of significance, $\geq 10^{3}$ colony-forming units (CFU)/mL with or without the appearance of systemic symptoms (fever $>38^{\circ} \mathrm{C}$ ) or local symptoms (purulent opening, insertion-site or route inflammation), determines the type of infectivity of the catheter. ${ }^{19}$ The removal of the catheter is preferable when it is a gateway to candidemia. Analysis of the culture of the catheter after its ablation is necessary in confirming infection. ${ }^{20,21}$

Since there is no specific technique by which to study the different types of infectivity of catheters contaminated by Candida spp., our study in the ICU at the University Hospital Center of Sidi Bel Abbe, Algeria aimed to adapt the BrunBuisson technique and previous specific bacterial definitions for the assessment of the different types of fungal infectivity of medical implants, and also to isolate and identify the involved species and calculate their corresponding rates. In addition to this, we aimed to investigate the formation of biofilms on catheter surfaces, using electronic imagery.

\section{Materials and methods}

Based on previous results obtained from a prevalence survey that was done in June 2009 by the Epidemiology Department of the University Hospital Center of Sidi Bel Abbes (unpublished data), we conducted this study in the ICU between February 2011 and January 2012. The samples of the implanted medical devices were taken from patients hospitalized for 48 hours or more. Candidemia is considered nosocomial when it first occurs 48 hours or more after hospital admission. ${ }^{7,22}$ Additionally, other samples were taken by swabbing the surface of the tongue. To transport the samples to the laboratory, a refrigerant bag was used.

\section{Patients}

The samples were taken directly from patients who presented the most important candidiasis risk factors (implanted medical devices, broad-spectrum antibiotic therapy, long stay in the ICU, etc). For every patient, the following data were registered: age, sex, antibiotic treatment, body temperature during the sampling, and presence or absence of inflammation and/or pus along the route of the catheter.

One patient agreed to photography of the tongue; this was a diabetic woman of 64 years who suffered from meningoencephalitis. She was treated by antibiotics, gentamicin and cephalosporin three times a day at dose levels of $100 \mathrm{mg} /$ day and $3 \mathrm{~g} /$ day, respectively, and acyclovir (900 $\mathrm{mg} \times 2 /$ day), vitamin $\mathrm{K}(10 \mathrm{mg})$, paracetamol ( $\mathrm{g} \times 3 /$ day $)$, and antidiabetic treatment (insulin, $3 \times 8 \mathrm{IU} /$ day). This patient died of a cardiac attack.

\section{Samples and yeast isolates}

We took samples based on the method of Boucherit-Atmani et al. ${ }^{15}$ Briefly, the implanted medical devices (catheters and other invasive medical devices) were taken directly from patients and placed in sterile Sabouraud liquid medium. After cutting the distal ends of the catheters, the tubes were opened in front of a torch, then rapidly flamed and sealed to avoid contamination. The tubes were then agitated in a vortex mixer for 1 minute, and purified strains were identified by a yeast identification system (API 32-C System; bioMériux, Marcy L'Etoile, France) and microculture (germ-tube and chlamydospore formation).

Tongue samples were collected by scraping the dorsum of the tongue with a sterile cotton swab, which was returned into the tube immediately after sampling. Then, the tube was agitated, and the different forms (yeast cells, hyphae, and pseudohyphae) were verified using light microscopy. In fact, scraping the surface of the tongue is a reliable method for detecting Candida spp. ${ }^{23}$

\section{Types of catheter infectivity}

The type of infectivity of each collected medical implant was assessed using the quantitative method of Brun-Buisson ${ }^{24}$ with some modifications. For this reason, the samples were vortexed for 1 minute, and then the yeasts were counted using a Thoma cell. To this end, a volume of the sample (after vortexing) was placed between the Thoma cell and the coverslip, and yeast cells were counted by light microscopy (magnification $\times 40$ ). Then, the calculation was reported in $\mathrm{CFU} / \mathrm{mL}$. When cell counting was difficult due to high density of the milieu, dilutions were performed.

The different types of catheter infectivity were determined by referring to the significance threshold, $\geq 10^{3} \mathrm{CFU} / \mathrm{mL}$, and to the systemic and/or local clinical symptoms. ${ }^{19}$

\section{Biofilms observation with SEM}

In order to highlight the formation of biofilms on the catheter surfaces, a central vascular catheter (CVC) and an orobronchial catheter (OBC) were removed from the aforementioned female patient after exposure times of 8 and 3 days, respectively. Biofilm samples were randomly selected and preserved with glutaraldehyde fixative (Sigma-Aldrich, St Louis, MO, USA), and sent to the SEM laboratory. 
Catheter-segment fixation was done according to the methods of Chandra et al. ${ }^{25}$ Briefly, biofilms of C. albicans on catheter segments were fixed with $2.5 \%(\mathrm{v} / \mathrm{v})$ glutaraldehyde in phosphate-buffered saline (PBS) (0.1 M, pH 7.4) and were introduced in sterile Eppendorf tubes that were sealed with an adhesive film, numbered, placed in another vial, and left for 12 hours at $4^{\circ} \mathrm{C}$ before shipment to the scanning electron microscope (SEM) laboratory for observations.

SEM preparation of the catheter's pieces was performed according to Chandra et al..$^{25}$ The samples were examined using a Hitachi S-4800 (Hitachi Ltd, Tokyo, Japan) fieldemission SEM by Dennis Kunkel Microscopy Inc (Kailua, HI, USA).

\section{Results and discussion}

The prevalence survey, which was conducted in June 2009 by the Epidemiology Department of the University Hospital Center of Sidi Bel Abbes, showed that $60 \%$ of the patients hospitalized in the ICU were victims of nosocomial infection, and the principal cause was the use of any type of catheter. In addition, this survey revealed widespread use of antibacterial agents, while antifungal agents were prescribed only in rare cases.

According to Avila-Aguero et al, ${ }^{11}$ previous use of antibiotics, endotracheal intubation, and use of central devices constitute the risk factors for candidemia infection. Effectively, catheters are the leading cause of bloodstream infection in patients in the ICU; ${ }^{26}$ half of all cases of candidemia occur in the ICU. ${ }^{27}$

In the present study, a total of 63 samples were taken from different implanted medical devices at the ICU during the study period. Twelve strains (19.04\%) of Candida spp. were isolated during the study period; nine strains of C. glabrata and only three strains of C. albicans were identified (Table 1).

Based on the results displayed in Table 1, C. glabrata was predominant compared with $C$. albicans; a ratio of 3:1 of $C$. glabrata versus $C$. albicans was observed.

The strains of $C$. albicans were isolated from the OBC and tongue of the female patient and from the $\mathrm{CVC}$ of another patient. The strains of $C$. glabrata were taken from different medical devices implanted into other patients.

In general, fungal infection in critically or seriously ill patients is a significant problem, ${ }^{16}$ and the use of indwelling devices, such as catheters, is a source of nosocomial infection..$^{5}$ In addition, the vast majority of the cases of candidemia occur in hospitalized patients; ${ }^{28}$ commonly affect patients in the ICU; and carry a high mortality risk. ${ }^{29}$

C. glabrata was previously thought to be a primarily nonpathogenic organism, but, in the past couple of decades, it has been increasingly recognized as a pathogen of problematic etiological origin in bloodstream infections. ${ }^{30-32}$ Additionally, this yeast has recently emerged as an important nosocomial pathogen, ${ }^{9,33,34}$ yet little is known about its epidemiology. ${ }^{33} \mathrm{In}$ fact, C. glabrata has been suggested to be the second most important human pathogen responsible for candidemia. ${ }^{35}$

According to Develoux and Bretagne, ${ }^{6}$ among the episodes of ICU candidemia, C. glabrata was the second most common causative species. ${ }^{10}$ However, a recent study found that no difference in mortality was associated with C. albicans and C. glabrata bloodstream infections. ${ }^{32,36}$ Trick et $\mathrm{l}^{37}$ have demonstrated that, among the Candida spp.,

Table I Results of the counting and identification of yeast strains isolated from implanted devices in the ICU

\begin{tabular}{|c|c|c|c|c|c|c|c|c|c|c|}
\hline \multicolumn{3}{|l|}{ Patients } & \multicolumn{6}{|c|}{ Sampling sites } & \multicolumn{2}{|c|}{ Count and identification } \\
\hline Sex, age & ATB & $\mathrm{T}\left({ }^{\circ} \mathrm{C}\right)^{\mathrm{a}}$ & CVC & PVC & TP & UP & OBC & Swab $^{b}$ & Count (cells/mL) & Isolated strains \\
\hline$F, 18$ & Gent + Ampi & 36.7 & & & $x$ & & & & $<10^{3}$ & C. glabrata \\
\hline M, 3I & Cefa + Cipr & 37.3 & & & $x$ & & & & $<10^{3}$ & C. glabrata \\
\hline M, 7I & Gent + Cipr & 38.1 & & & $x$ & & & & $>10^{3}$ & C. glabrata \\
\hline \multirow[t]{2}{*}{$F, 64$} & Gent + Cipr + Aclv & 37.1 & & & & & $x$ & & $>10^{3}$ & C. albicans \\
\hline & & & & & & & & $\mathrm{x}$ & - & C. albicans \\
\hline \multirow[t]{2}{*}{ M, 23} & Gent + Cipr & 38.7 & & & & $x$ & & & $>10^{3}$ & C. glabrata \\
\hline & & & & $x$ & & & & & $<10^{3}$ & C. glabrata \\
\hline $\mathrm{F}, \mathrm{I7}$ & - & 37.6 & $x$ & & & & & & $<10^{3}$ & C. glabrata \\
\hline$F, 57$ & Cefa + Oxa & 38.4 & $x$ & & & & & & $<10^{3}$ & C. glabrata \\
\hline$M, 66$ & $A m p+$ Cefo & 37.3 & & & & $x$ & & & $<10^{3}$ & C. albicans \\
\hline$F, 4 \mathrm{I}$ & Cefa + Oxa & 38.0 & & $x$ & & & & & $>10^{3}$ & C. glabrata \\
\hline$F, 46$ & - & 37.0 & & $x$ & & & & & $>10^{3}$ & C. glabrata \\
\hline
\end{tabular}

Notes: aPatient's temperature at the time of sampling; 'swabbing of the patient's tongue.

Abbreviations: F, female; M, male; ATB, antibiotic therapy; Gent, gentamicin; Ampi, ampicillin; Cefa, cefazolin; Cipr, ciprofloxacin; Aclv, acyclovir; Oxa, oxacillin; Cefo, cefotaxime; CVC, central venous catheter; PVC, peripheral venous catheter; TP, tracheotomic probe; UP, urinary probe; OBC, orobronchial catheter; C. glabrata, Candida glabrata; C. albicans, Candida albicans. 
the rate of C. glabrata has increased as a cause of bloodstream infection in American ICUs since 1993.

\section{Types of catheter infectivity}

Figure 1 shows the results of the types of catheter infectivity. In total, three different types were observed: six (9.52\%) cases were contaminations, two $(3.17 \%)$ cases were colonizations, and three $(4.76 \%)$ cases were infections. The distinction between these different infectivity types was made according to previous definitions, ${ }^{19,24}$ and the counting of the yeast cells was accomplished using Thoma cells and the collected clinical data. These same observations were also distinguished in all the other medical departments of the University Hospital Center mentioned above (Seddiki et al, unpublished data, 2012).

Similarly to Carrière and Marchandin, ${ }^{19}$ three different types of catheter infectivity were reported: contamination, colonization, and infection. The rate of contamination of catheters was higher than the rates of colonization and infection; this explains, in part, the difficulty in diagnosis of catheter-related candidiasis.

The increase in acquired fungal infections in hospital, particularly in candidiasis, has been attributed to the ability of fungi to adhere to the invasive devices that are used for treatment. ${ }^{38}$ According to Bleichner et al, ${ }^{39}$ the frequency of isolation of Candida spp. in catheter-related infections ranges from $2 \%$ to $5 \% .{ }^{39}$ However, catheter-related infection is preceded by the colonization of the distal end of the catheter, and quantitative culture must be used to confirm that the catheter is the source of the signs of infection. ${ }^{19}$

Figure 2 shows the $\mathrm{OBC}$ colonized by C. albicans in the previously described patient. The count of yeast cells isolated from this catheter was higher than $10^{3}$ cells $/ \mathrm{mL}$ (Brun-Buisson technique). The patient's temperature during the sampling was $37.1^{\circ} \mathrm{C}$; however, the patient was given an infusion solution of paracetamol, which prevented an increase of temperature,

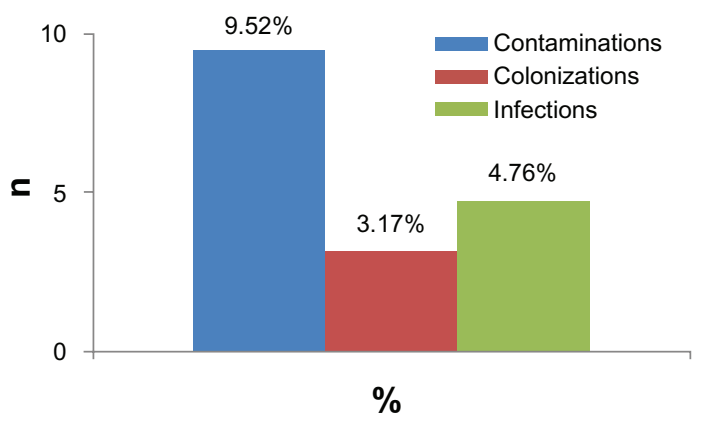

Figure I Rates of different types of infectivity of implanted medical devices observed in the intensive care unit.

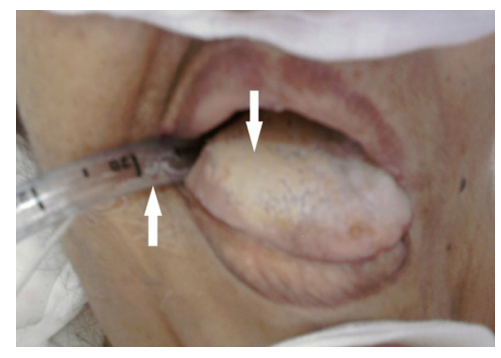

Figure 2 Microbial propagation between the patient's tongue and the implanted orobronchial catheter.

Note: Arrows indicate a white carpet of Candida albicans on the infected patient's tongue and the observed $C$. albicans biofilm on the orobronchial catheter.

and the same patient was also treated with broad-spectrum antibiotics. We also observed a white carpet on the patient's tongue, from which the isolate strain revealed C. albicans.

The observation of the sample (swabbing of the tongue surface) under an optical microscope revealed the existence of yeast cells and elongated hyphal forms. Interestingly, these different forms exist in the biofilms of C. albicans; ${ }^{25}$ thus, it is possible that this carpet was a biofilm of C. albicans, and it may possibly have indicated a dissemination of this yeast between the tongue and the $\mathrm{OBC}$ implanted in the neighboring area.

Fungi have the ability to adhere not only to human tissues, but also to any invasive devices. ${ }^{38}$ In fact, the acquisition of C. albicans in the ICU seems to be mainly endogenous. ${ }^{40,41}$ Oropharyngeal candidiasis is a common opportunistic infection occurring in immunocompromised patients. ${ }^{42}$ It appears as a white, elevated, mossy substance attached to the tongue surface or oral mucosa. ${ }^{43,44}$ It has been reported that oral C. albicans colonization increases remarkably in diabetic patients, especially in women with diabetes. ${ }^{45}$ In addition, biofilms contribute to the pathogenesis of oral candidiasis, ${ }^{46}$ and its presence on the surface of medical implants may constitute a risk factor for persistent candidiasis. ${ }^{15,47}$

In our study, most of the patients (including this one) had been treated with broad-spectrum antibacterial agents. Candida colonization, indeed, is strongly linked to the receipt of antibiotics, particularly broad-spectrum ones. ${ }^{48}$
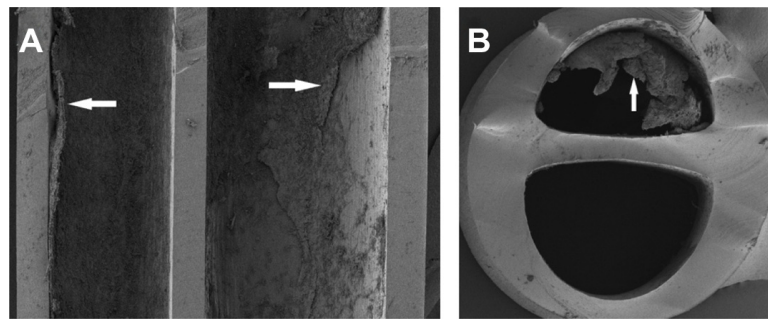

Figure 3 SEM of (A) longitudinal and (B) lateral cuts performed on the CVC. Notes: Arrows indicate a layer of Candida albicans biofilm attached to the inner surface of the CVC. Magnification $\times 35$.

Abbreviations: SEM, scanning electron microscope; CVC, central venous catheter. 

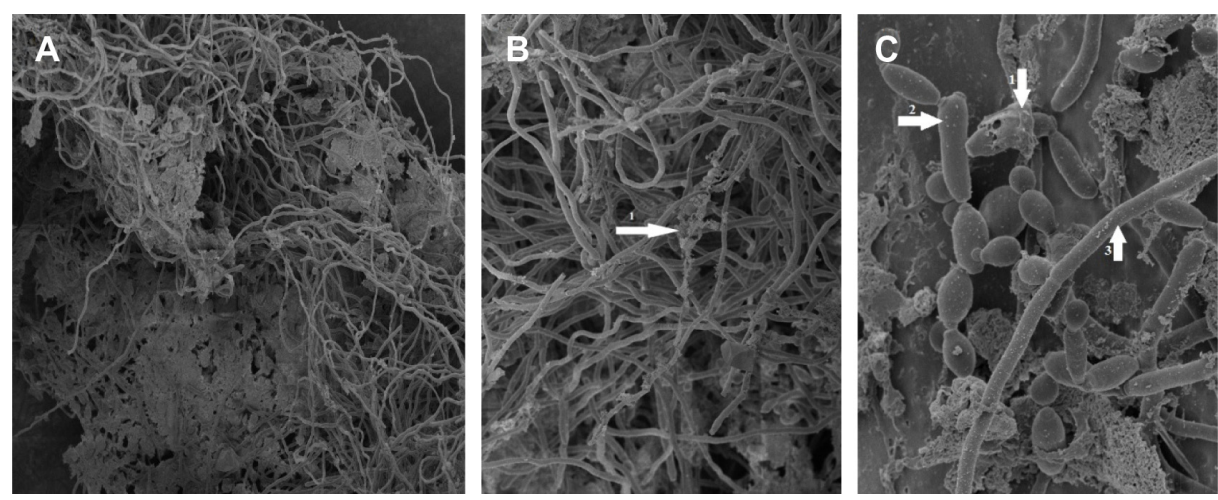

Figure 4 SEM of a mixture of morphological forms of Candida albicans biofilm developed on the inner surface of the CVC. Magnification: $($ A $) \times 450$; (B) $\times$ I I00; (C) $\times 4500$. Notes: Arrows: I = ECM; 2 = pseudohypha; 3 = hypha.

Abbreviations: SEM, scanning electron microscope; CVC, central venous catheter; ECM, extracellular matrix.

\section{Biofilm observation with SEM}

C. albicans biofilm from the inner surface of the CVC segments was examined and imaged with SEM.

Longitudinal and lateral cuts performed on the CVC (Figure 3A and B, respectively) revealed a dense layer of C. albicans biofilm attached to the inner surface of the CVC; however, its external surface was not affected by the biofilm.

With higher magnifications of SEM, the structure of the biofilm could be demonstrated. Figure $4 \mathrm{~A}-\mathrm{C}$ shows a mixture of morphological forms of $C$. albicans biofilm. This biofilm revealed a dense network of yeasts, pseudohyphae, and hyphae. The extracellular matrix was also observed; it coated cells and hyphae.

The $\mathrm{OBC}$ of the female patient was contaminated by C. albicans biofilm. This is shown clearly in Figure 5, which also shows the complex structure of the biofilm. C. albicans biofilm was formed by yeast cells, pseudohyphae, hyphae, and a visible matrix.

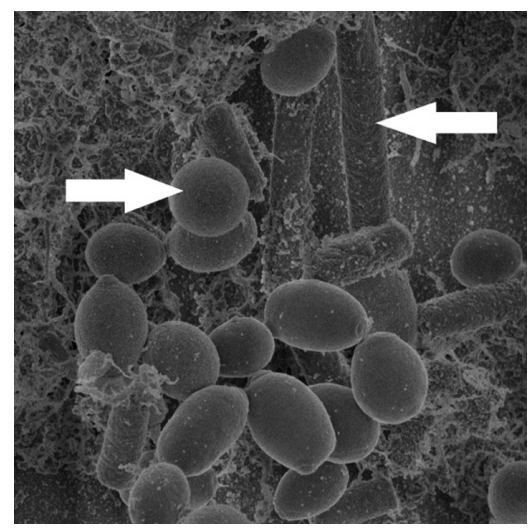

Figure 5 SEM of the contaminated OBC showing Candida albicans biofilm. Notes: Arrows indicate a yeast cell and hypha. Magnification $\times 6000$. Abbreviations: SEM, scanning electron microscope; OBC, orobronchial catheter.
In Andes et al, ${ }^{49}$ the SEM of the biofilm on catheter segments demonstrated more clearly the heterogeneous architecture of the biofilm structure. In their work, SEM of in vivo $C$. albicans biofilm showed a mature biofilm that consisted of a dense network of yeasts cells, hyphae, and pseudohyphae. Further, the same results were observed by Hawser and Douglas ${ }^{50} 10$ years before.

In addition, biofilms of $C$. albicans consist of matrixenclosed microcolonies containing yeasts, hyphae, and pseudohyphae. The biofilm is arranged in a bilayer structure ${ }^{51}$ consisting of a thin yeast layer and an upper hyphal layer. ${ }^{52} \mathrm{In}$ a recent study, the structure of the biofilm was investigated using SEM, and this study, indeed, revealed an extracellular matrix material coating the cells. ${ }^{53}$ In fact, adjacent to the catheter surface, yeast cells were densely embedded in an extracellular matrix. ${ }^{48}$

\section{Conclusion}

Progress in the medical field is constantly evolving; however, clinical, epidemiological, and microbiological studies have so far failed to prevent nosocomial infections and, in particular, those of fungal origin. The current study is, to the authors' knowledge, the first survey of an ICU in Algeria. It highlights the nosocomial candidemia related to medical implants (catheters, probes, intubations, etc) by calculating their rates and by determining the causative strains and the various types of catheter infectivity. These infections, in fact, are serious additional risks acquired by critically ill patients who require significant intensive care.

According to the literature, there is no accepted method by which to evaluate the types of catheter fungal infectivity. Within this frame, our study has shown that the Brun-Buisson method seems to be suitable for these studies. Our results revealed three different types 
of catheter infectivity: contaminations $(9.52 \%)$, infections (4.76\%), and colonizations (3.17\%). In addition, the results prove that $C$. glabrata was strongly involved in the contamination of catheters; this species was more frequently isolated from the implanted medical devices than C. albicans.

On the other hand, SEM revealed the formation of biofilms of $C$. albicans on the surfaces of the catheters. Consequently, biofilms constitute a major problem in the diagnosis of candidiasis.

To conclude, it is highly recommended that vigilance be exercised when using medical implants to prevent fungal infections, especially in ICUs. To this end, in developing countries, the surveillance of nosocomial infections caused by fungi remains an open discussion, and further studies are warranted in this field.

\section{Acknowledgments}

The authors express great appreciation for the support provided by Prof Bertrand Dupont. We also wish to thank Mr Brahim Yala, teacher of English, for reviewing and correcting this manuscript.

\section{Disclosure}

The authors report no conflicts of interest in this work.

\section{References}

1. Vandijck D, Blot S, Labeau S, et al. Candidemia in critically ill patients: An analysis of daily antifungal therapy related costs. J Mycol Med. 2008;18(2):96-99.

2. Falagas ME, Roussos N, Vardakas KZ. Relative frequency of albicans and the various non-albicans Candida spp among candidemia isolates from inpatients in various parts of the world: a systematic review. Int J Infect Dis. 2010;14(11):e954-e966.

3. Eloy O, Marque S, Mourvilliers B, et al. Contribution of the Pittet's index, antigen assay, IgM, and total antibodies in the diagnosis of invasive candidiasis in intensive care unit. J Mycol Med. 2006; 16(3):113-118.

4. Eggimann P, Pittet D. Candidoses en réanimation [Candidiasis in the ICU]. Réanimation. 2002;11:209-221. French.

5. Seabra R, Bhogal N. Hospital infections, animal models and alternatives. Eur J Clin Microbiol Infect Dis. 2009;28(6):561-568.

6. Develoux M, Bretagne S. Candidiasis and yeast infections. EMCMaladies Infectieuses. 2005;2(3):119-139.

7. Gürcüoğlu E, Akalın H, Ener B, et al. Nosocomial candidemia in adults: Risk and prognostic factors. J Mycol Med. 2010;20(4):269-278.

8. Maknia F, Sellamia A, Trabelsi H, et al. Yeast species isolated in the CHU of Sfax, Tunisia. J Mycol Med. 2010;20(1):42-47.

9. Moran C, Grussemeyer CA, Spalding JR, Benjamin DK Jr, Reed SD. Comparison of costs, length of stay, and mortality associated with Candida glabrata and Candida albicans bloodstream infections. Am J Infect Control. 2010;38(1):78-80.

10. Ruan SY, Lee LN, Jerng JS, Yu CJ, Hsueh PR. Candida glabrata fungaemia in intensive care units. Clin Microbiol Infect. 2008;14(2):136-140.

11. Avila-Aguero ML, Canas-Coto A, Ulloa-Gutierrez R, Caro MA, Alfaro B, Paris MM. Risk factors for Candida infections in a neonatal intensive care unit in Costa Rica. Int J Infect Dis. 2005;9(2):90-95.
12. Picazo JJ, González-Romo F, Candel FJ. Candidemia in the critically ill patient. Int J Antimicrob Agents. 2008;32 Suppl 2:S83-S85.

13. Ramage G, Saville SP, Thomas DP, López-Ribot JL. Candida biofilms: an update. Eukaryotic Cell. 2005;4(4):633-638.

14. Khan S, Alam F, Azam A, Khan AU. Gold nanoparticles enhance methylene blue-induced photodynamic therapy: a novel therapeutic approach to inhibit Candida albicans biofilm. Intl J Nanomedicine. 2012;7:3245-3257.

15. Boucherit-Atmani Z, Seddiki SML, Boucherit K, Sari-Belkharoubi L, Kunkel D. Candida albicans biofilms formed into catheters and probes and their resistance to amphotericin B. J Mycol Med. 2011;21(3): 182-187.

16. Soni N, Wagstaff A. Fungal infection. Curr Anaesth Crit Care. 2005; 16(4):231-241.

17. Veyssier P, Domart Y, Liebbe AM. Infections Nosocomiales [Nosocomial Infections], 2nd ed. Paris: Collection Abrégés de Médecine; 1998. French.

18. Pittet D, Monod M, Suter PM, Frenk E, Auckenthaler R. Candida colonization and subsequent infections in critically ill surgical patients. Ann Surg. 1994;220(6):751-758.

19. Carrière C, Marchandin H. Infections liées aux cathéters veineux centraux: diagnostic et definitions [Infection linked to central venous catheters: diagnosis and definitions]. Néphrologie. 2001;22(8):433-437. French.

20. Timsit JF, Wolff M, Mourvillier B, Schortgen F, Régnier B. Diagnosis and management of catheter-related infections in the ICU. Méd Mal Infect. 2003;33(12):619-627.

21. Gallien S, Sordet F, Enache-Angoulvant A. Treatment of catheterrelated candidemia. J Mycol Med. 2007;17(1):42-49.

22. Blot SI, Vandewoude KH, Hoste EA, Colardyn FA. Effects of nosocomial candidemia on outcomes of critically ill patients. Am J Med. 2002;113(6):480-485.

23. Kadir T, Pisiriciler R, Akyüz S, Yarat A, Emekli N, Ipbüker A. Mycological and cytological examination of oral candidal carriage in diabetic patients and non-diabetic control subjects: thorough analysis of local aetiologic and systemic factors. J Oral Rehabil. 2002;29(5):452-457.

24. Brun-Buisson C, Abrouk F, Legrand P, Huet Y, Larabi S, Rapin M. Diagnosis of central venous catheter-related sepsis: Critical level of quantitative tip cultures. Arch Intern Med. 1987;147(5):873-877.

25. Chandra J, Mukherjee PK, Ghannoum MA. In vitro growth and analysis of Candida biofilms. Nat Protoc. 2008;3(12):1909-1924.

26. Timsit JF, Dubois Y, Minet C, et al. New materials and devices for preventing catheter-related infections. Ann Intensive Care. 2011;1:34.

27. Almirante B, Rodríguez D, Park BJ, et al; Barcelona Candidemia Project Study Group. Epidemiology and predictors of mortality in cases of Candida bloodstream infection: results from population-based surveillance, Barcelona, Spain, from 2002 to 2003. J Clin Microbiol. 2005;43(4):1829-1835.

28. Kettani A, Belkhadir ZH, Mosadik A, et al. Antifungal treatment of systemic candidiasis in intensive care unit. J Mycol Med. 2006; 16(1):16-25.

29. Chalmers CM, Bal AM. Management of fungal infections in the intensive care unit: a survey of UK practice. Br J Anaesth. 2011; 106(6):827-831.

30. Clark TA, Hajjeh RA. Recent trends in the epidemiology of invasive mycoses. Curr Opin Infect Dis. 2002;15(6):569-574.

31. Fidel PL Jr, Vazquez JA, Sobel JD. Candida glabrata: review of epidemiology, pathogenesis, and clinical disease with comparison to C. albicans. Clin Microbiol Rev. 1999;12(1):80-96.

32. Ruan SY, Huang YT, Chu CC, Yu CJ, Hsueh PR. Candida glabrata fungaemia in a tertiary centre in Taiwan: antifungal susceptibility and outcomes. Int J Antimicrob Agents. 2009;34(3):236-239.

33. Hajjeh RA, Sofair AN, Harrison LH, et al. Incidence of bloodstream infections due to Candida species and in vitro susceptibilities of isolates collected from 1998 to 2000 in a population-based active surveillance program. J Clin Microbiol. 2004;42(4):1519-1527. 
34. Tortorano AM, Caspani L, Rigoni AL, Biraghi E, Sicignano A, Viviani MA. Candidiasis in the intensive care unit: a 20 -year survey. J Hosp Infect. 2004;57(1):8-13.

35. Pfaller MA, Messer SA, Hollis RJ, et al. Trends in species distribution and susceptibility to fluconazole among blood stream isolates of Candida species in the United States. Diagn Microbiol Infect Dis. 1999;33(4):217-222.

36. Klevay MJ, Ernst EJ, Hollanbaugh JL, Miller JG, Pfaller MA, Diekema DJ. Therapy and outcome of Candida glabrata versus Candida albicans bloodstream infection. Diagn Microbiol Infect Dis. 2008;60(3):273-277.

37. Trick WE, Fridkin SK, Edwards JR, Hajjeh RA, Gaynes RP; National Nosocomial Infections Surveillance System Hospitals. Secular trend of hospital-acquired candidemia among intensive care unit patients in the United States during 1989-1999. Clin Infect Dis. 2002;35(5):627-630.

38. Verstrepen KJ, Reynolds TB, Fink GR. Origins of variation in the fungal cell surface. Nat Rev Microbiol. 2004;2(7):533-540.

39. Bleichner G, Beaucaire G, Gottot $S$, et al. Infections liées aux cathéters veineux centraux en reanimation [Infections related to central venous catheters in intensive care]. Réan Urg. 1994;3:321-330. French.

40. Abbes S, Sellami H, Sellami A, et al. Variability of Candida albicans strains in ICU in Tunisia hospital. J Mycol Med. 2008;18(1):10-15.

41. Bouza E, Muñoz P. Epidemiology of candidemia in intensive care units; Int J Antimicrob Agents. 2008;32 Suppl 2:S87-S91.

42. Nairy HM, Charyulu NR, Shetty VA, Prabhakara P. A pseudorandomised clinical trial of in situ gels of fluconazole for the treatment of oropharngeal candidiasis. Trials. 2011;12:99.

43. Hoshi N, Mori H, Taguchi H, et al. Management of oral candidiasis in denture wearers. J Prosthodont Res. 2011;55(1):48-52.
44. Yang YL, Lo HJ, Hung CC, Li Y. Effect of prolonged HAART on oral colonization with Candida and candidiasis. BMC Infect Dis. 2006;6:8.

45. Javed F, Klingspor L, Sundin U, Altamash M, Klinge B, Engström PE. Periodontal conditions, oral Candida albicans and salivary proteins in type 2 diabetic subjects with emphasis on gender. BMC Oral Health. 2009;9:12.

46. Thein ZM, Samaranayake YH, Samaranayake LP. Characteristics of dual species Candida biofilms on denture acrylic surfaces. Arch Oral Biol. 2007;52(12):1200-1208.

47. Mukherjee PK, Chandra J. Candida biofilm resistance. Drug Resist Updat. 2004;7(4-5):301-309.

48. Ha JF, Italiano CM, Heath CH, Shih S, Rea S, Wood FM. Candidemia and invasive candidiasis: a review of the literature for the burns surgeon. Burns. 2011;37(2):181-195.

49. Andes D, Nett J, Oschel P, Albrecht R, Marchillo K, Pitula A. Development and Characterization of an in vivo central venous catheter Candida albicans biofilm model. Infect Immun. 2004; 72(10):6023-6031.

50. Hawser SP, Douglas LJ. Biofilm formation by Candida species on the surface of catheter materials in vitro. Infect Immun. 1994;62(3):915-921.

51. Douglas LJ. Medical importance of biofilms in Candida infections. Rev Iberoam Micol. 2002;19(3):139-143.

52. Douglas LJ. Candida biofilms and their role in infection. Trends Microbiol. 2003;11(1):30-36.

53. Nett JE, Sanchez H, Cain MT, Ross KM, Andes DR. Interface of Candida albicans biofilm matrix-associated drug resistance and cell wall integrity regulation. Eukaryotic Cell. 2011;10(12):1660-1669.
International Journal of General Medicine

\section{Publish your work in this journal}

The International Journal of General Medicine is an international, peer-reviewed open-access journal that focuses on general and internal medicine, pathogenesis, epidemiology, diagnosis, monitoring and treatment protocols. The journal is characterized by the rapid reporting of reviews, original research and clinical studies across all disease areas.

\section{Dovepress}

A key focus is the elucidation of disease processes and management protocols resulting in improved outcomes for the patient.The manuscript management system is completely online and includes a very quick and fair peer-review system. Visit http://www.dovepress.com/ testimonials.php to read real quotes from published authors. 